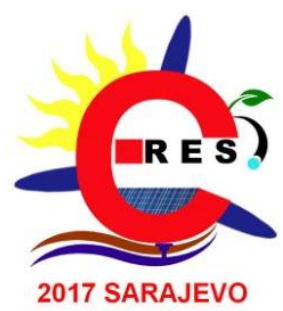

\title{
POWER ELECTRONIC CONVERTERS WITHOUT ELECTROLYTIC CAPACITORS
}

\author{
Alex Van den Bossche ${ }^{1}$, Salim Haddad $^{2}$, Mourad Mordjaoui ${ }^{3}$ \\ ${ }^{1}$ EELAB Ghent University, Belgium \\ ${ }^{2,3}$ LGMM Laboratory, University of 20 aout 1955 - Skikda
}

\begin{abstract}
Power electronic converters may have a quite long lifetime, but some applications such as converters for automotive and photovoltaic could even desire a longer life. One of the elements to increase the lifetime of converters is to avoid electrolytic capacitors, They can be replaced by metalized film capacitors or ceramic capacitors. A lot of converter types can be re-designed to use them, but it influences the way of designing, as a lower capacitance value is used.

Electrolytic capacitors are one of the elements that reduce the lifetime of power electronic converters gradually an adapted design can avoid that electrolytic capacitors have to be used in converters. A range of examples can be shown from fractions of watts up to Gigawatt. For example gate drive circuits, single and three-phase converters where film capacitors are used in the DC link, high voltage DC converters. These techniques are useful to prolong the life of converters and to allow higher ambient temperatures, typical application domains are PV and other grid connected converters, converters for battery charging and general electric vehicle applications.
\end{abstract}

Keywords: Power electronic converters, Electrolytic capacitor, lifetime.

\section{Introduction}

A lifetime is determined by the shortest life of a component which cannot be easily repaired. Also the environment can influence the lifetime, such as thermal effects, humidity, pollution, overvoltage and over current. For electronic elements, the correct packaging, protection and housing are important; it helps using automotive grade components. Active power electronic elements need mainly the correct voltage, current and thermal design. The environment may affect also the contacts, avoiding multiple contacts in series; some silicone oil may protect them. Electrolytic capacitors have a limited lifetime by thermal ageing combined with voltage. In warmer countries their limited lifetime may even dominate the lifetime of the converter $[1,2]$. The aim of the paper is that converters without electrolytic capacitors can be realized from very small to very large.

\section{Capacitor types}

Power electronics was using electrolytic capacitors during decades. The ageing process is as follows: electrolytic capacitors degrade as electrolysis continues, oxygen increases the oxide layer, hydrogen disappears, the water disappears, contacts get corroded. During the life, the capacitance is reduced and the Equivalent Series Resistance, ESR, increases significantly, so that more self-heating occurs, which accelerates the process.

Corresponding author: s.haddad@univ-skikda.dz 
The failure rate after burn in is some $10^{-6} / \mathrm{h}$, but the failure probability rises a lot after 50000 hours, 5 years of continuous operation, or 10 years discontinuous, so that the converter life is significantly shorter than the PV panels. It even gets worse at a higher ambient temperature. At the boiling temperatures of the electrolyte $(\mathrm{KOH}+\mathrm{glycol}+\mathrm{water}$, about $110^{\circ} \mathrm{C}$ ) only a few hours of lifetime are available.

Also storing during two years may increase the leakage current so much that overheating can occur. So a good way is if the electrolytic capacitors cannot be avoided, to limit their number, or at least the temperature and voltage. Alt cold temperature the ESR increases due to a lower mobility of ions. Small capacitor values can be obtained with ceramic types COG material grade have a very good loss factor, but take more space, XR7 is reasonable in losses but has a smaller size and cost. A good order of magnitude is $1 \mathrm{~A} / 100 \mu \mathrm{F}$ for electrolytic capacitors at $100 \mathrm{~Hz}, 1 \mathrm{~A} / \mu \mathrm{F}$ at $1 \mathrm{kHz}$ above $1 \mathrm{kHz}$ and $1 \mathrm{~A} / 10 \mathrm{nF}$ above $100 \mathrm{kHz}$ for ceramic low loss capacitors, Class 1, COG or NPO types.

Up to now, low losses film capacitors are dominated by polypropylene: tests on capacitors show a long life up to $100^{\circ} \mathrm{C}$ hot spot temperature, a few hours at $140^{\circ} \mathrm{C}$. The degradation is gradual: the self-healing reduces the capacitance makes less surface active and a small increase of loss factor. No special changes are observed at lower temperatures. Some comprehensive overview is given in [4].

\section{Oscillator}

Most of oscillators assume a low impedant power supply where an electrolytic capacitor is used in the DC-bus. A traditional oscillator is a Colpitts oscillator circuit where the feedback is realised in a capacitive way [5]. However, if the scheme is rearranged, the capacitors remain low and a quite high resistance value can make the link to the supply. Fig. 1 shows a type up to $400 \mathrm{~V}$, which uses a transistor hacked from a compact fluorescent lamp (CFL). The advantage of such oscillators is that it can directly operate from a larger voltage and does inject very little current ripple in the supply, this means that no electrolytic capacitor is needed there (Figs.1, 2, 3).

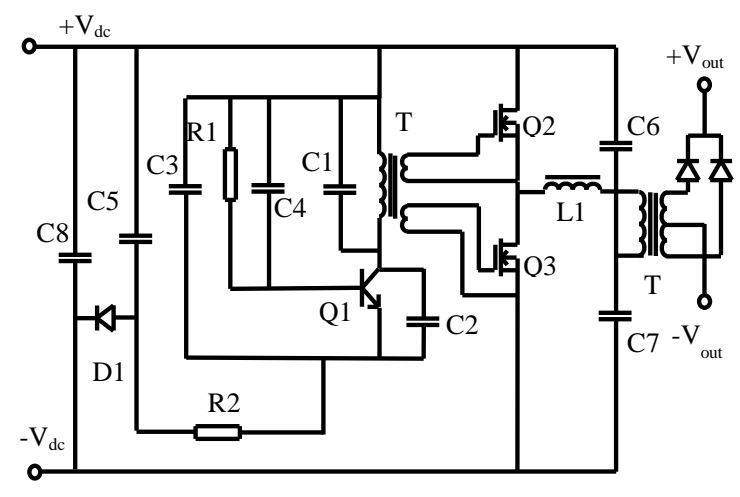

Figure 1. High voltage Colpits oscillator without the need for electrolytic capacitors, even in the supply

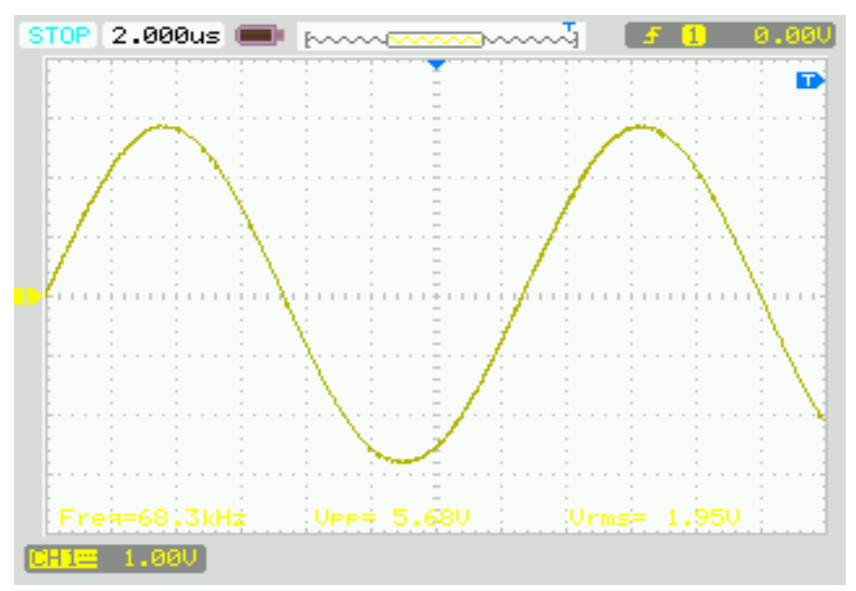

Figure 2. Waveform obtained in this oscillator 


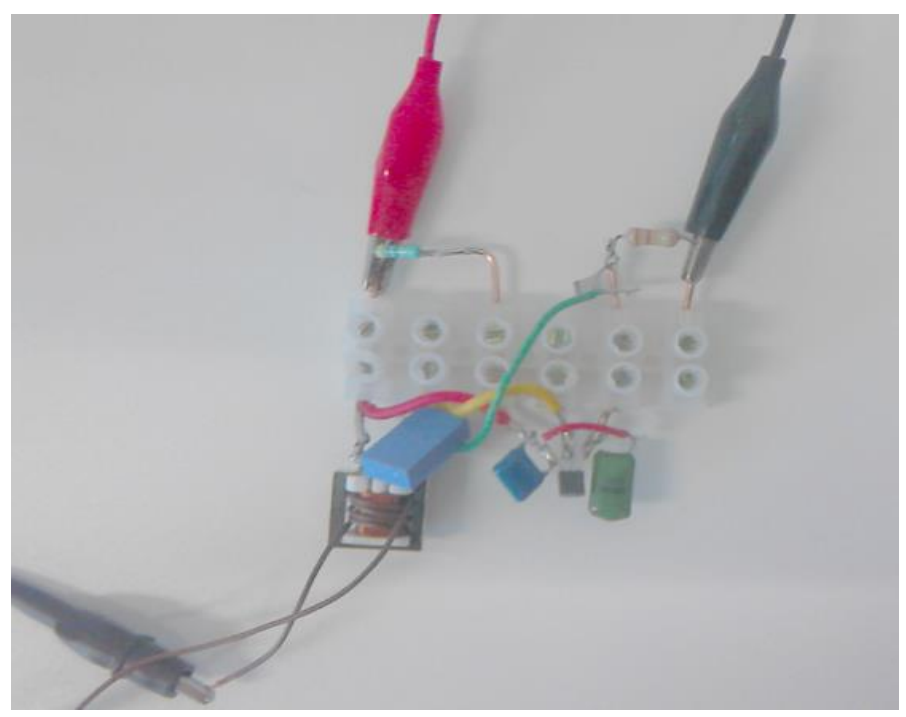

Figure 3. Experimental circuit using hacked components form a CFL lamp.

Other papers show higher voltage oscillators using two Mosfets [6] or Mosfet PNP for (very) small power supplies. The oscillator topologies can be used for driving a half bridge even for faster applications such as $\mathrm{SiC}$ or $\mathrm{GaN}$ [7].

\section{Gate drives}

If a small transformer is used for each driver, this problem is solved. This small transformer can be "hacked" from types such as common mode filters. They may have a good insulation, end the leakage inductance is quite high but might be used for resonance or to make it short circuit proof. The cost of 6 small transformers is less than one complicated large one. And one can avoid electrolytic capacitors.

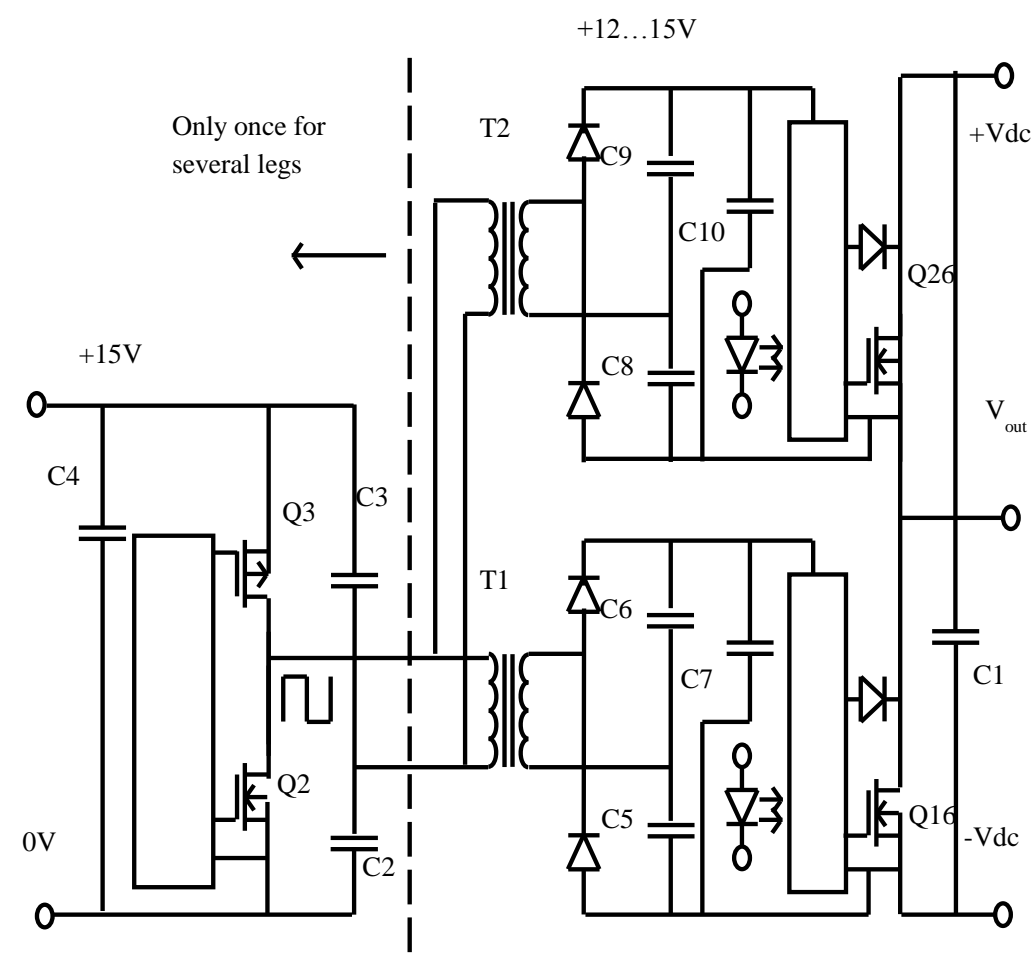

Figure 4.Gate drive circuit without electrolytic capacitors, used in [8] 


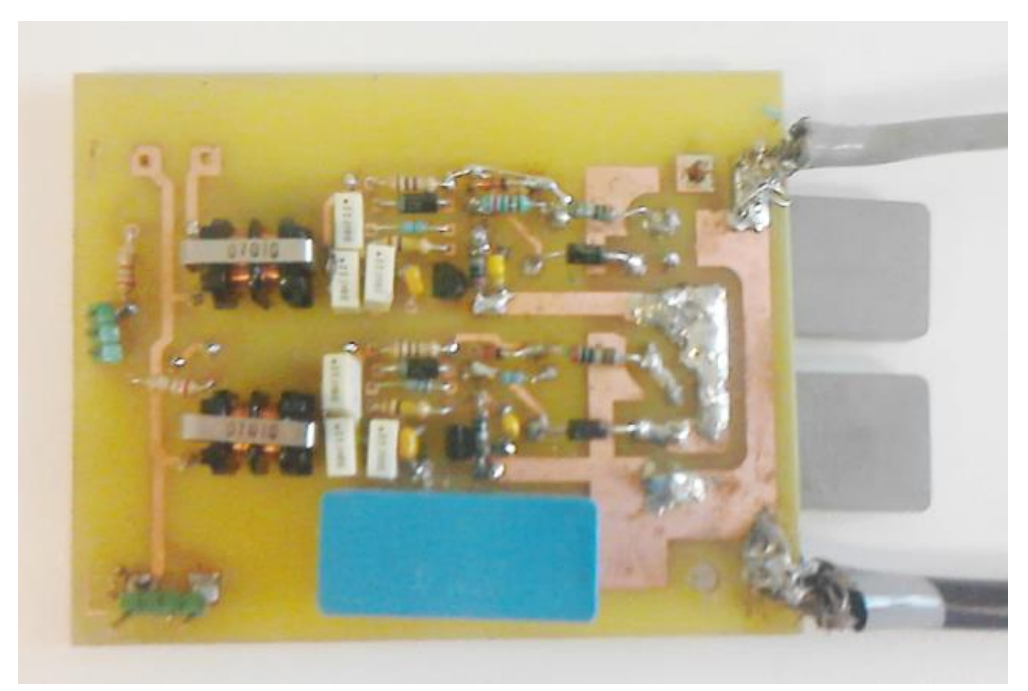

Figure 5. One leg using Isolated gate driver without electrolytic capacitors

For aerospace, film capacitors are replaced by ceramic capacitors and also opto-couplers are avoided as they do not withstand designs using $200^{\circ} \mathrm{C}$ junction and $150^{\circ} \mathrm{C}$ case. [9].

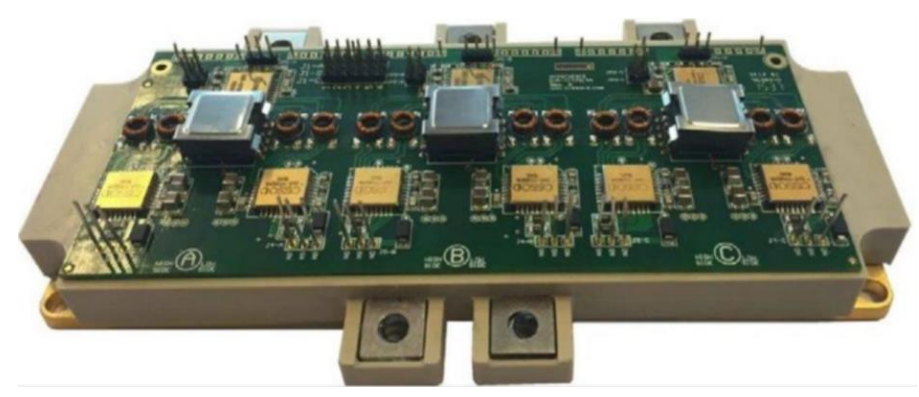

Figure 6. A converter concept for extreme temperatures [9]

Level shifters are often chosen as do not use magnetic components, but often need electrolytic capacitors to keep the charge for enough time. This can be a half grid period if the output of the leg is a square wave. There might be a need for electrolytic capacitors in the upper drive, and also in the lower DC supply. If the upper transistor is turned on first, the upper driver supply is not charged, and the transistor is not turned on. Not much designers are aware of it.

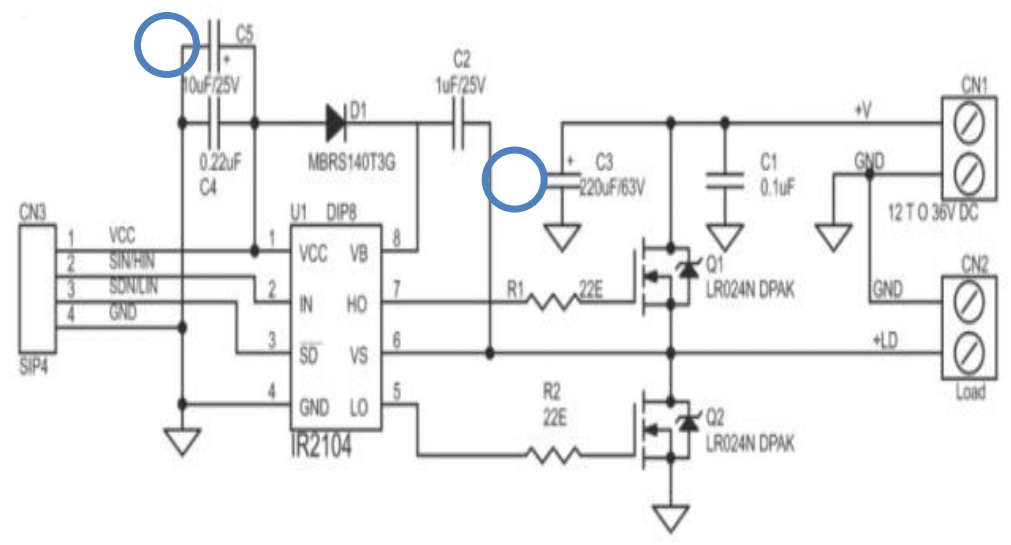

Figure 7. Electrolytic Capacitors in level shifters 


\section{Single phase $P V$ inverter}

Normally, the panels produce a slow changing power depending on the local solar radiation. The power to the grid is a superposition of a sine wave and a $100 \mathrm{~Hz}$ component. At unity power factor, the amplitude of the $100 \mathrm{~Hz}$ component equals the DC component, so the energy to store is $\mathrm{Pdc}^{*}(2 / \mathrm{pi})^{*} \mathrm{~T} / 2=0.5^{\wedge} \mathrm{C}^{*}\left(\mathrm{Vmax}^{\wedge} 2-\mathrm{V} \min ^{\wedge} 2\right)$ and the capacitor:

$$
\begin{gathered}
\mathrm{C}=\mathrm{T}^{*}(2 / \mathrm{pi}) * \mathrm{Pdc} /(\mathrm{Vmax} \wedge 2-\mathrm{Vmin} \wedge 2) \\
\mathrm{C}=\mathrm{T} / 2 *(2 / \mathrm{pi}) * \mathrm{Pdc} /[(\mathrm{Vmax}+\mathrm{Vmin}) / 2 *(\mathrm{Vmax}-\mathrm{Vmin})] \\
\mathrm{C}=\mathrm{T} / \mathrm{pi} * \mathrm{Pdc} /[(\mathrm{Vmax}+\mathrm{Vmin}) / 2 *(\mathrm{~V} \max -\mathrm{V} \min )]
\end{gathered}
$$

We take a design example of $1 \mathrm{~kW}$. For a voltage of $350 \mathrm{~V}$ average and a ripple of $35 \mathrm{~V} p \mathrm{p}$

$$
\begin{gathered}
\mathrm{C}=0.02 / \mathrm{pi}^{*} 1000 / 35 / 350=520 \mu \mathrm{F} \\
0,02 / 3,14159 * 1000 / 350 / 35
\end{gathered}
$$

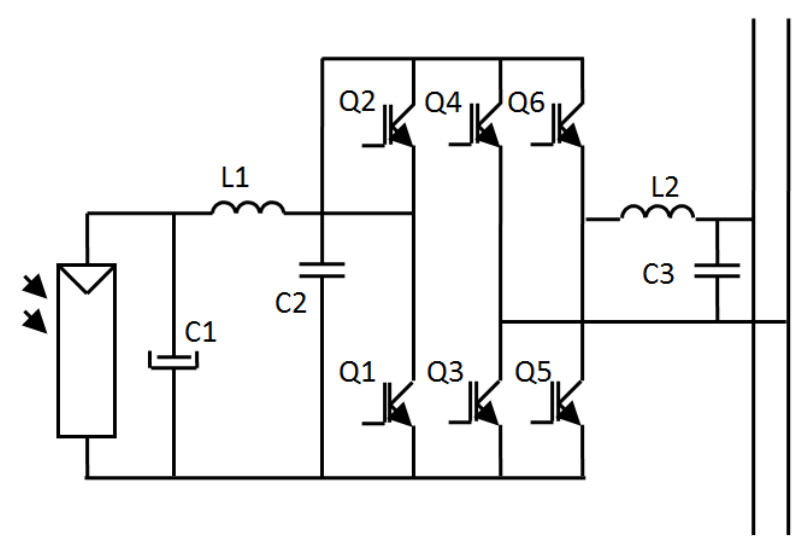

Figure 8. A topology where the electrolytic capacitor can be serviced

Peak rectifying: $2.7 \mathrm{~A} * 0.01 / 0.5 \mathrm{~m}=54 \mathrm{~V}$

In fact an electrolytic capacitor has quite a lot of capacitance, and is often chosen for a low Equivalent Series Resistor (ESR) for obtaining low losses rather than for a high energy. If the electrolytic capacitor is put at the input, a rather easy servicing is possible. An end of life can be detected by a higher HF ripple or higher temperature [10], In three-phase it can be omitted [11,12]. Also the inductive components can be improved in those topologies [12]. Another scheme allows suppressing the electrolytic if the DC link is allowed to change a lot.

The same type of equation can be used, but if $550 \mathrm{~V}$ average is used, minimal $325 \mathrm{~V}$ max $675 \mathrm{~V}$; $350 \mathrm{Vpp}$ ripple a much smaller capacitor value can be used.

\section{$0,02 / 3,14159 * 1000 / 550 / 350=33.1 \mu \mathrm{F}$}

A $33 \mu \mathrm{F}$ film capacitor can handle the associated voltage and current ripple.

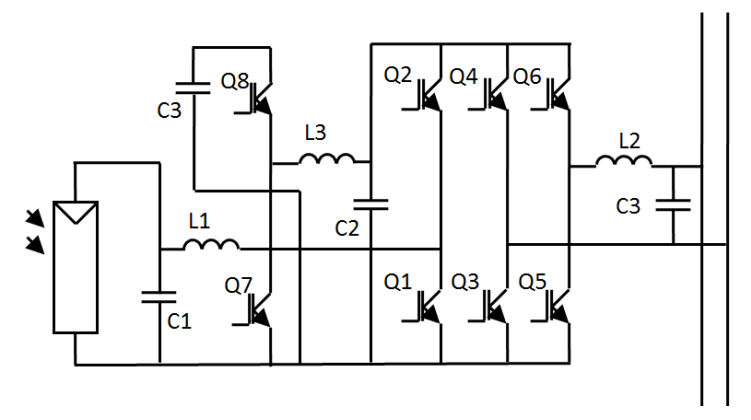

Figure 8. Single phase topology without electrolytic capacitors 
This value would overheated by such a voltage ripple when using electrolytic capacitors, but is feasible in film capacitors, even smaller capacitors can be put in parallel for better cooling.

The advantage is that it is much cheaper and smaller than an electrolytic capacitor. The disadvantage is more switching losses. But this can be tackled with SiC transistors. Anyhow, the designer is free to take another compromise with lower ripple if it would be optimal. For stability reasons, $\mathrm{C} 1$ will have to be larger than $\mathrm{C} 2$. Another way of designing is to put the electrolytic capacitors completely at the input and use a film capacitor in the DC-link. It has the advantage to reduce the switching losses. The electrolytic capacitor is subjected to a lower ripple (continuous current). And if the electrolytic capacitor fails, it can be easier replaced as it is only wired to the input and an inductor.

\section{High voltage Multiple Module Converters}

In principle many variants are possible [14], but MMC solutions tend to dominate. A high voltage DC transmission may handle some $500 \mathrm{MW}$ at some $500 \mathrm{kV} .500 \mathrm{kV}$ line to line means some $700 \mathrm{kV}$ peak. Even if a module carries $7000 \mathrm{~V}$ average DC bus, it still needs 100 of them in series and 6 in total for a full converter. Moreover, if the module has $0.1 \%$ loss, it still counts for $500 \mathrm{~kW}$. Electrolytic capacitors are made for $400-500 \mathrm{~V}$. it means about 20 capacitors in series $1000 \mathrm{~A} 15 \mathrm{~ms}$ is $15 \mathrm{C}$, it needs some $500 \mathrm{mF}, 30 \mathrm{~V}$ pp ripple, $\tan$ delta $=10 \%$

$1000 \mathrm{~A} * 30 \mathrm{~V} / 4 * 20 * 0.1=15 \mathrm{~kW}$ losses/module $\rightarrow \mathrm{x} 600 \rightarrow 9 \mathrm{MW}$ over the total converter. In film capacitors rather $3000 \mathrm{~V}$ ripple is tolerated, but tan delta $0.1 \% 1000 \mathrm{~A} \mathrm{rms} * 3000 \mathrm{~V} / 8 * 0.001=375 \mathrm{~W} ? \rightarrow * 600=225 \mathrm{~kW}$ which is more reasonable In combination, with high voltage transistors, or IGCT, and low loss inductors, efficiencies beyond $99.8 \%$ can be reached $100 * 1000 * 3=300 \mathrm{~kW} / \mathrm{leg} \rightarrow 900 \mathrm{~kW}$ inductors $300 \mathrm{~kW}$ and conductors $300 \mathrm{~kW}$. Together $1.5 \mathrm{MW}$ or $99.7 \%$ efficiency. It is difficult to reach that in another type of technology.

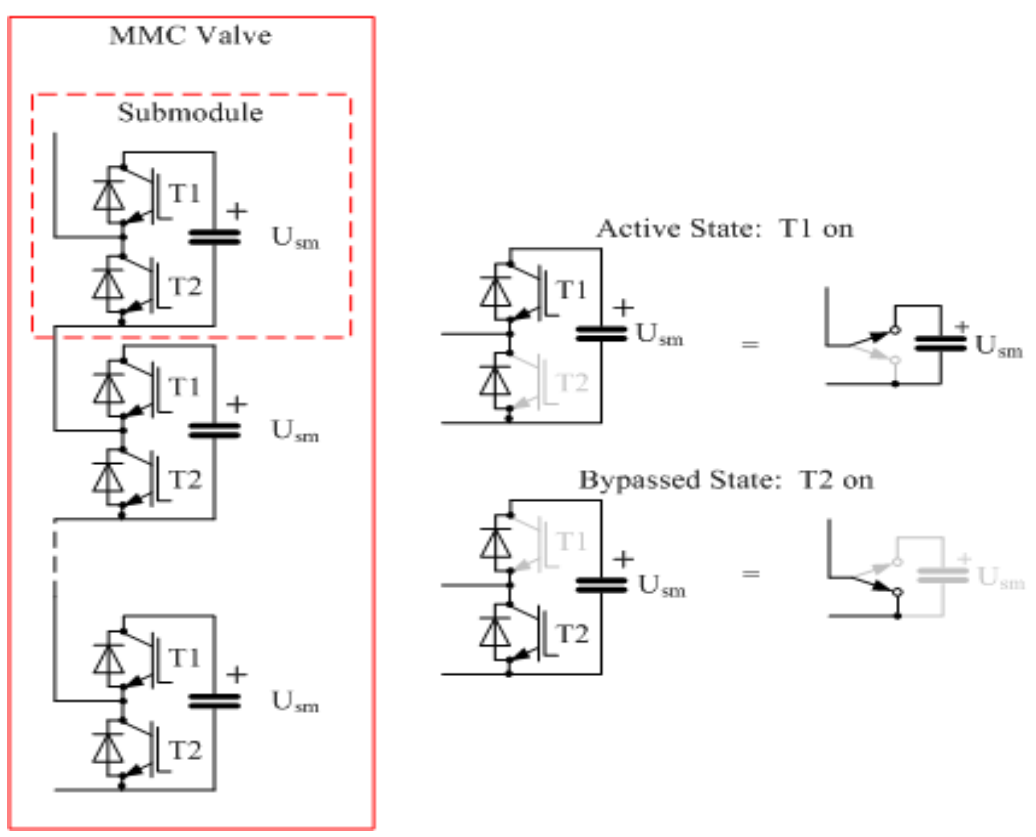

Figure 9. Modular modules: half bridge + capacitor

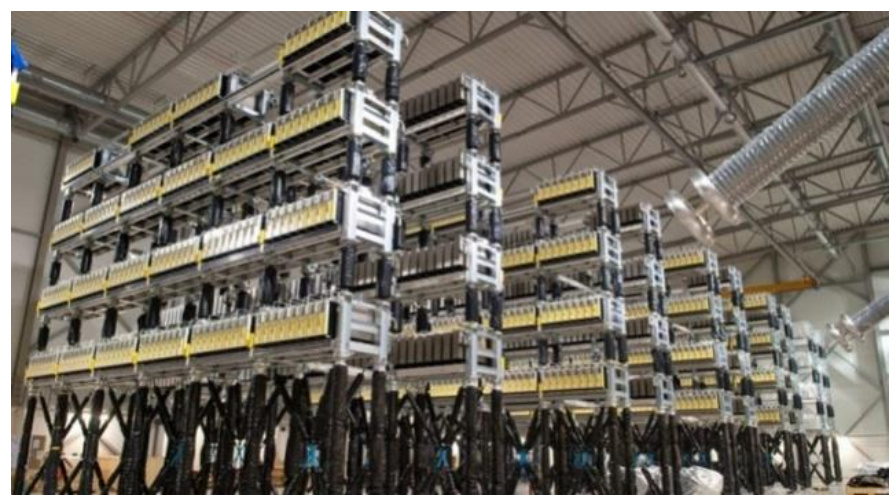

Figure 10. High voltage MMC: Modular Mutilevel converters [15] 


\section{Final paper improvements}

More work will be done in having the correct equations and description, but this draft could give an impression of what the contents could be. Equations will be more elaborated and not only numerical and changed into the in MSword type. Also topologies for battery charging equipment can use electrolyte less designs, which is an intermediate power.

\section{Conclusion}

From very low power and only $100 \mathrm{~V}$ to very large power up to $1000 \mathrm{kV}$, converters without electrolytic capacitors make sense. This is true for the power circuit as well down to the internal power supplies, and gate drives.

\section{References}

[1] Wang, H., \& Blaabjerg, F. Reliability of capacitors for DC-link applications in power electronic converters-An overview. IEEE Transactions on Industry Applications, 50(5), 3569-3578. (2014)

[2] Jantsch, M., \& Verhoeve, C. W. G. (1997). Inverters with three phase output and without electrolyte capacitor for improved lifetime, efficiency and costs of grid connected systems. Netherlands Energy Research Foundation ECN. (1997).

[3] Bikorimana, J. M. V., \& Van den Bossche, A. Lifetime comparison for film capacitor compared to electrolytic in the PV converter DC link. In $3^{\text {rd }}$ International Conference on Electrical, Electronics, Engineering Trends, Communication, Optimization and Sciences (EEECOS)-2016. (2016).

[4] Cercle "Radios anciennes" http://radioman64.e-monsite.com/pages/documentations/condensateurs/technologie-descondensateurs.html

[5] Horowitz, Paul, and Winfield Hill. The art of electronics. Cambridge [England]: Cambridge University Press. (1989).

[6] Low stand by power, self-oscillating power supply Alex Van den Bossche UGent, Georgi Nikolov and Vencislav Valchev 2007 EUROPEAN CONFERENCE ON POWER ELECTRONICS AND APPLICATIONS, VOLS 1-10. p.1286-1292, (2007).

[7] Orlin Stanchev, Emilian Bekov, Alex van den Bossche, "Self-oscillating gate driver used for gallium nitride transistors in high frequency applications", Electrical Apparatus and Technologies (SIELA), 2016 19th International Symposium on. 29 May-1 June 2016

[8] Jean Marie Vianney Bikorimana and Alex Van den Bossche. "Using Numerical Inverse Laplace for Optimizing the Current Control in Grid Coupled Inverters." In International Conference on Electro-Energy, Proceedings, 13-17. Skikda University: Skikda University. (2014).

[9] Dave Hutton, "Delivering first SiC Intelligent Power Modules to Thales CISSOID” Bodo's Power Systems June 2016 page 10.

[10] Van den Bossche, Alex, Jean Marie Vianney Bikorimana, and Firgan Nihatov Feradov. 2014. "Reduced Losses in PV Converters by Modulation of the DC Link Voltage." In International Conference on Renewable Energies and Power Quality, 1-6. EA4EPQ.

[11] Mohannad Jabbar Mnati, Alex Van den Bossche, and Jean Marie Vianney Bikorimana, "Design of A Half-Bridge Bootstrap Circuit For Grid Inverter Application Controlled By Pic24fj128ga010”, 20-23 November 2016, ICRERA’2016 conference, Birmingham City in UK

[12] Alex Van den Bossche, "New Design Trends in Photovoltaic Converters." In $5^{\text {ième }}$ Conférence Internationale Sur Le Génie Electrique, Proceedings, ed. Mohammed Tamali, 1-7. Bechar, Algéria: Université de Bechar Algérie. (2013)

[13] Van den Bossche, Alex, and V VALCHEV. Inductors and Transformers for Power Electronics. CRC Press. (2005).

[14] Ajami, A., Oskuee, M. R. J., Mokhberdoran, A., \& Van den Bossche, A. Developed cascaded multilevel inverter topology to minimise the number of circuit devices and voltage stresses of switches. IET Power Electronics, 7(2), 459466. (2013).

[15] supergrid web site:http://www.think-grid.org/supergrid 